Artigo

\title{
A LUTA AMBIENTALISTA NA BAHIA: UM ESTUDO DE CASO SOBRE O MOVIMENTO PELA SOBERANIA POPULAR NA MINERAÇÃO NO ALTO SERTÃO BAIANO
}

\author{
THE ENVIRONMENTAL FIGHT IN BAHIA: A CASE STUDY ON THE MOVE BY \\ POPULAR SOVEREIGNTY IN MINING IN HIGH SERTÃO BAIANO
}

\author{
LA LUCHA MEDIOAMBIENTAL EN BAHIA: UN ESTUDIO DE CASO SOBRE EL \\ MOVIMIENTO POR SOBERANÍA POPULAR EN LA MINERÍA EN ALTO SERTÍO \\ BAIANO
}

\section{Ana Paula Melo Fernandes Rodrigues}

\begin{abstract}
Resumo
A pesquisa em questão trata-se de um estudo com abordagem qualitativa, exploratória, do tipo bibliográfico. O presente estudo parte das seguintes questões norteadoras como os movimentos sociais podem contribuir para resistência e mobilização de problemas socioambientais? Como as contradições do desenvolvimento podem ser analisadas na educação ambiental? Para tanto, $\mathrm{O}$ trabalho foi dividindo em quatro seções, na seção I trata-se do desenvolvimento na era capitalista e a correlação na utilização dos bens naturais, bem como na distribuição de consequências socioambientais, na Seção II abordam a educação ambiental e o processo de institucionalização como disciplina e discursão de conceitos, nesse contexto, a Seção III traz a proposta compreender o movimento ambientalista no Brasil, relata-se o modo como se põem em práticas neoliberais seus espaços estratégicos de atuação e de enfretamentos, em seguida, a atenção se dirige ao que está em disputa na atividade de mineração nomeando a seção IV - Movimento dos atingidos pela Mineração-MAM em que faz uma reflexão da atividade de mineração no País e seu desrespeito com direitos humanos, no tocante as causas sangrentas socioambientais, mostrando as Lutas do MAM com a discursão da política contraditória do modelo atual de exploração mineral. Por fim, os movimentos sociais são importantes porque representam alguma demanda social, política e econômica, muitas vezes as ações, demandas e princípios articulados pelos pleitos coletivos podem modificar e/ou interferir nas políticas públicas, realidades sociais entre outros.
\end{abstract}

\begin{abstract}
This research is a study with a qualitative, exploratory, bibliographic approach. The present study starts from the following guiding questions: how can social movements contribute to resistance and mobilization of socio-environmental problems? How can development contradictions be analyzed in environmental education? Therefore, It was divided into four sections, in the section I, it is spoken about development in the capitalist era and the correlation in the use of natural goods, in section II address environmental education and the institutionalization process as a discipline and discussion of concepts, in that context, Section III proposes to understand the environmental movement in Brazil, it reports the way in which neoliberal practices put their strategic spaces of action and confrontations, then It pays attention to what is in dispute in the mining activity by naming section IV - Movement of those affected by Mining-MAM in which it reflects on the mining activity in the country and its disrespect for human rights, with regard to bloody socioenvironmental causes, showing the struggles of MAM with the discourse of the contradictory policy of the current model of mineral exploration. Finally, social movements are important because they represent some social demand, political and economic, often the actions,
\end{abstract}


demands and principles articulated by collective claims can modify and / or interfere in public policies, social realities, among others.

\section{Resumen}

La investigación en cuestión es un estudio con un enfoque cualitativo, exploratorio, bibliográfico. El presente estudio parte de las siguientes preguntas orientadoras: ¿cómo pueden los movimientos sociales contribuir a la resistencia y la movilización de los problemas socioambientales? ¿Cómo se pueden analizar las contradicciones del desarrollo en la educación ambiental? Para eso, el trabajo se dividió en cuatro secciones, en la sección I se trata del desarrollo en la era capitalista y la correlación en el uso de bienes naturales, así como en la distribución de las consecuencias socioambientales, en la Sección II se ocupan de la educación ambiental y el proceso de La institucionalización como disciplina y discurso de conceptos, en este contexto, la Sección III propone comprender el movimiento ambiental en Brasil, informa la forma en que las prácticas neoliberales ponen sus espacios estratégicos de acción y confrontación, luego, atención aborda lo que está en disputa en la actividad minera al nombrar la sección IV - Movimiento de los afectados por Mining-MAM en el que reflexiona sobre la actividad minera en el país y su falta de respeto por los derechos humanos, con respecto a las sangrientas causas socioambientales, mostrando las luchas de MAM con el discurso de la política contradictoria del modelo actual de exploración minera. Finalmente, los movimientos sociales son importantes porque representan una demanda social, política y económica, a menudo las acciones, demandas y principios articulados por demandas colectivas pueden modificar y / o interferir en las políticas públicas, las realidades sociales, entre otros.

Palavras-Chave: Luta Ambientalista; Mineração; Movimento Popular.

Keywords: Environmentalist Struggle; Mining; Popular Movement.

Palabras clave: lucha ambientalista; Minería; Movimiento Popular.

\section{INTRODUÇÃO}

Os Movimentos Sociais contribuem positivamente para educação ambiental transformadora no sentido que seu legado de atuação como forma ativa e em conjunto das demandadas coletivas pode interferir nas pretensões dos que deles se opõem. Gonh, (2006 p.32) salienta que há modificação social histórica de um país causado pela participação dos movimentos, essas transformações geradas poderão ser tanto progressistas quanto conservador ou reacionário, "dependendo das forças sociopolíticas a que estão articulados, em suas densas redes; e dos projetos políticos que constroem com suas ações. Eles têm como base de suporte entidades e organizações da sociedade civil e política".

Abordar educação ambiental na perspectiva de ressignificação no sentido de que ela ultrapassa as inquietações com os aspectos biológicos da vida, sua importância não se limita em discutir questões e ações que garantam a preservação de bens naturais como determinadas espécies de vegetais e animais. O seu papel é contribuir para uma educação de empoderamento do indivíduo para a compreensão de questões ambientais que fazem parte de consequências de questões sociais e políticas (PAZ, 2017). É crucial que as questões relativas ao meio ambiente passem a ser tratadas para além do que a ecologia aborda, ou seja, não separando as questões ambientais das questões sociais. Nesse contexto a educação ambiental não deve ser discutida separada da educação, ela é educação tendo em vista que ela se desenvolve no meio social. 
Nessa perspectiva, as reflexões propostas por Paulo Freire podem contribuir significativamente para o educador ambiental, uma vez que evidenciando como pressuposto da práxis educativa o diálogo na construção do conhecimento, há permanente reflexão e problematização, além da compreensão crítica da realidade e a transformação social. Para substanciar, a educação ambiental possui a responsabilidade de que uma nova ética seja construída, Loureiro (2012 p. 59) nos direciona para compreender a educação ambiental como ecológica sob condições na qual "definida no embate democrático entre ideias e projetos que buscam a hegemonia na sociedade e no modo como nesta produz e se reproduz problematizando valores vistos como absolutos e universais". Demonstrando as diferenças comunidade e sua moral o que pode ser bom, justo e solidário para determinados grupos pode "não ser para outra que esteja em uma situação objetiva diversa".

Assim ao trabalhar com educação ambiental contribui no aspecto ativo dos pares provocando um novo olhar capaz de promover mudanças não apenas no indivíduo, como também no seu entorno, como importante aliado no processo de transformação e valorização do espaço em que coabitam. A contribuição acadêmica dessa investigação é relevante uma vez que fazendo uma busca com o descritor "movimentos sociais e educação ambiental" no catalogo de teses e dissertações da capes só aparece um trabalho, da autora Magacho (2017) nesse trabalho foi investigado que relações têm sido estabelecidas entre movimentos sociais e Educação Ambiental na produção teórica, teses e dissertações em Educação Ambiental no país e mapear a produção sobre os movimentos sociais no campo educação ambiental.

O objetivo dessa pesquisa foi elaborar uma revisão literária que envolva a educação ambiental e os movimentos sociais, procurando reforçar o aporte e o legado das ações dos movimentos sociais e suas contribuições na comunidade. No entanto é pertinente salientar que a atuação dos movimentos está condicionado ao espaço geográfico, cultural e social, carece de condições e problemas adversos do outro. Considerando as lacunas do conhecimento sobre esta temática, quanto é favorável contribuir para um desenvolvimento comunitário local e transformação social justificou a realização desse trabalho.

O artigo foi construído partindo das seguintes questões norteadoras, como os movimentos sociais podem contribuir para resistência e mobilização de problemas socioambientais? Como as contradições do desenvolvimento podem ser analisadas na educação ambiental? Para tanto, $O$ trabalho foi dividindo em quatro seções, na seção I trata-se do desenvolvimento na era capitalista e a correlação na utilização dos bens naturais, bem como na distribuição de consequências socioambientais, na Seção II abordam a educação ambiental e o processo de institucionalização como disciplina e discursão de conceitos, nesse contexto, a Seção III traz a proposta compreender o movimento ambientalista no Brasil, relata-se o modo como se põem em práticas neoliberais seus espaços estratégicos de atuação e de enfretamentos, em seguida, a atenção se dirige ao que está em disputa na atividade de mineração nomeando a seção IV Movimento dos atingidos pela Mineração-MAM em que faz uma reflexão da atividade de mineração no País e seu desrespeito com direitos humanos, no tocante as causas sangrentas socioambientais, mostrando as Lutas do MAM com a discursão da política contraditória do modelo atual de exploração mineral. 


\section{O HOMEM E A NATUREZA: O NEOLIBERALISMO E AS CONTRADIÇÕES DO DESENVOLVIMENTO}

O ser humano desde primórdios de sua existência no planeta já se relaciona com a natureza, essa relação se afirma pela necessidade do uso dos recursos naturais para sobrevivência, no passado sua utilização se desenvolvia de maneira artesanal, agrária, extrativista, baseada nas manufaturas, seu encadeamento era fundamentada na percepção das experiências, por tentativas e repetições, assim havia o uso sincronizados com a natureza. A exploração do ser humano na natureza afirma a necessidade intrínseca a sua existência no planeta fazendo uso das palavras de Karl Marx, o homem é uma parte da natureza.

Esse modelo de uso sustentável da natureza sofreu profundas mudanças a partir da revolução industrial com utilização em larga escala dos bens naturais, modelo industrial de produção em massa em consequência, aumentou também a degradação do meio ambiente. O sistema capitalismo com objetivo comercial e acumulo de lucro com plano de fundo o desenvolvimento das tecnologias pôde ser percebido nas mudanças de comportamento social advindas do consumo em massa, da alienação, da exploração. Essa concepção capitalista descontrola o mecanismo natural de uso e reposição natural da terra conforme explicada na metodologia de Mark (1983), para compreender a afirmação capitalista entre a sociedade e a natureza.

O planeta terra tem sofrido marcas profundas pela cultura capitalismo, em que incentiva ao consumo desenfreado, prática de uma cultura "O potencial destrutivo gerado pelo desenvolvimento capitalista o colocou numa posição negativa com relação à natureza" (GADOTTI, 2000 p.31). A exploração dos bens naturais de forma insustentável na sociedade moderna desencadeia uma desigualdade social provocada pela utilização de uma classe social dominante que detém do capital, explorado objetivo individual e cunho lucrativo. Dialogamos com Grossi, (2013 p.34) que reporta à questão ambiental correlacionado a desigualdade das classes no acesso aos bens ambientais naturais e na distribuição dos efeitos perversos da degradação ambiental, delineados contradições deliberadas pelo capitalismo na relação entre sociedade e natureza. "Nosso posicionamento político se pauta na defesa do caráter coletivo dos bens ambientais, como indispensáveis a vida humana e á sua reprodução, onde a questão do acesso a estes bens se constitui num direito público e universal". Alertando o poder aquisitivo dominante sobre propriedade do povo ora usurpado.

Ainda no tocante as diferenças sociais fomentadas pelo modelo atual de produção Foladori (2001), frisa o desencadeamento de uma série de consequências negativas e até catastróficas no meio ambiente destacando-se a forma como as diferentes classes sociais são atingidas. São notáveis as pessoas em maiores condições de vulnerabilidade social recebem maiores impactos da destruição socioambiental em detrimento de uma parcela dominante das quais desfrutam de um amplo contingente de bens ambientais e suas consequências recaem em menor proporção do que o outro grupo causando o que é conhecido por alguns autores com injustiça ambiental.

Nesse contexto injustiça ambiental é definhada como um conjunto de regras que certifiquem que nenhum grupo de pessoas seja de classe, étnicos, raciais "suporte uma parcela desproporcional das consequências ambientais 
negativas geradas de operações econômicas e políticas" e programas governamentais, "bem como resultantes da ausência ou omissão de tais políticas" (HERCULANO, 2006, p. 2).

\section{A EDUCAÇÃO AMBIENTAL NO BRASIL: PERCURSO HISTÓRICO DE INSTITUCIONALIZAÇÃO}

$\mathrm{Na}$ atual conjuntura sobre os bens ambientais Leff (2001 p. 49), deixa claro o impacto da exploração econômica sobre a natureza, a destruição ecológica e a escassez dos recursos "não são problemas gerados por processos naturais, mas determinados pelas formas sociais e pelos padrões tecnológicos de apropriação e exploração econômica da natureza". A partir desse cenário muito se discute a educação ambiental como assunto relevante e como ferramenta de transformação social em diversos contextos locais e mundiais.

O tema foi palco de muitos debates na ceara de formação conceitual. $O$ primeiro seminário internacional sobre educação ambiental realizado Estocolmo em 1972, definiu objetivos e fundamentos, evidenciou-se seu papel na luta contra a pobreza, analfabetismo e equalizar as distribuições de riquezas, Já em 1977 ocorreu na $1^{\circ}$ conferência intergovernamental em Tbilisi na Geórgia alargando as discursões sobres às estratégias da $E A$, quando o indivíduo e comunidade toma consciência de seu meio ambiente, obtém o conhecimento, as habilidades, os valores, as experiências e a determinação que os tornem aptos a agir individual e coletivo para solucionar problemas ambientais em um processo contínuo (CARVALHO, 2001).

Para Carvalho (2001) no Brasil começou a institucionalizar essa temática no seminário das políticas públicas 1981 com a promulgação da lei federal no 6938/81 que instalou a Política Nacional do Meio Ambiente (PNEA) incorporando a importância da EA com um caminho para superar os problemas ambientais, sendo ofertado tanto ensino formal e não formal. Em 1988 a educação ambiental foi incorporada a constituição federal no capítulo IV art.225 e, contudo as principais políticas públicas intensificadas a partir da conferência sobre meio ambiente e desenvolvimento Rio 92 ocorreu na cidade do Rio de Janeiro e teve como meta a busca por caminhos para conciliar sócio econômico e a conservação da natureza partir de diálogos entre empresas, terceiro setor 1e movimentos sociais. Nesse mesmo ano a nação foi presenteada o ministério do meio ambiente (MMA).

Em 1994 inspirados nesses eventos o MMA e o ministério da educação e cultura (MEC) elaboraram o programa nacional da Educação Ambiental (PRONEA) em que buscou romper a ideia dualista de homem/ natureza, entendendo que o ser humano é parte integrante da natureza. (CARVALHO, 2001).

A Lei de Diretrizes e Bases da Educação Nacional (LDB), Lei 9394/96, reafirma os princípios definidos na Constituição com relação à $E A$ : será considerada na concepção dos conteúdos curriculares de todos os níveis de ensino, sem constituir disciplina específica, implicando desenvolvimento de hábitos e atitudes sadias de conservação ambiental e respeito à natureza, a

\footnotetext{
${ }^{1}$ Terceiro setor organizações sem fins lucrativos, que atuam na área social, como ONGs, entidades filantrópicas, empresas cidadãs, Fundações, associações comunitárias (Gohn, 2000).
} 
partir do cotidiano da vida, da escola e da sociedade. Em 2012 foram definidas as Diretrizes Curriculares Nacionais (DCN) para a Educação Ambiental. A partir da definição dessas diretrizes, de acordo com os Parâmetros Curricular Nacional, foram intensificados os processos de inserção da EA no contexto escolar.

Por sua vez existem diferenças no conceito de educação ambiental, para alguns está estreitamente vinculada aos recursos naturais e o meio ambiente para outros ela transpõe essas causas atribuindo um artefato de caráter social e político de educação, depende do olhar, das crenças, das vivências e objetivos do sujeito que a investiga. Layrargues e Lima (2014) identificaram três macrotendências pedagógicas sobre pesquisa nesse assunto: conservacionista, pragmática e a crítica. A primeira decorre supervalorização do homem pela natureza e transformação ambiental sem reconhecer a questão capitalista, a segunda buscar o paradigma do desenvolvimento sustentável e consumo consciente, voltando se a senários urbanos, preocupação com o lixo que passa ser considerado resíduo sólido e por fim contrapondo as linhas anteriores, a linha crítica que dialoga a compreensão político-ideológica tem suas raízes nas relações socioculturais e de classes construídas historicamente e devem ser inseridas no debate ambiental.

Para Loureiro (2012 p. 34), a educação ambiental se justifica na "ação conscientizadora é mútua, envolve capacidade crítica, diálogo e assimilação de diferentes saberes, e a transformação ativa da realidade e das condições de vida". Ela e capaz de promover a "conscientização e esta se dá na relação entre o 'eu' e o 'outro', pela prática social reflexiva e fundamentada teoricamente".

Corrobora nessa dimensão os ensinamentos de Paulo Freire (1979: 1981), considerando o ser humano como ser social, histórico e inacabado é constituído na relação com sigo mesmo, com a natureza e com os outros, é possível concluir que ele se constitui na dinâmica cultural da qual ele está sendo inserido ao modificar o ambiente ele também se modifica.

\title{
O MOVIMENTO AMBIENTALISTA NO BRASIL: BREVE HISTÓRICO.
}

Há muitos posicionamentos quanto ao conceito de movimentos sociais, partindo da definição teórica sobre movimentos sociais dialogamos com Gohn (2000, p. 13).

\begin{abstract}
Ações coletivas de caráter sociopolítico, construídas por atores sociais pertencentes a diferentes classes e camadas sociais. Eles politizam suas demandas e criam um campo político de força social na sociedade civil. Suas ações estruturam-se a partir de repertórios criados sobre temas e problemas em situações de: conflitos, litígios e disputas. As ações desenvolvem um processo social e políticocultural que cria uma identidade coletiva ao movimento, a partir de interesses em comum. Esta identidade decorre da força do princípio da solidariedade e é construída a partir da base referencial de valores culturais e políticos compartilhados pelo grupo.
\end{abstract}

Nas palavras da autora em cena os movimentos sociais nascem de causas, ideias e valores comuns de determinados grupos de classes e camadas sociais diferentes que têm características seja elas sociais, políticas econômicas com algum elo que fomenta as demandas do coletivo, formando assim processo identificatório coletivo. Eles são capazes de gerar inovações na esfera politicas 
colaborando para transformação e desenvolvimento de sociedade civil e política. "O tipo de ação social envolvida é que será o indicador do caráter do movimento". Podemos ter movimentos reformistas, transformadores, retentores e alternativos (GOHN, 2000, p.14).

No tocante aos movimentos sociais com bandeira de luta os bens ambientais muitas vezes se justificam nas injustiças ambientais que afirma nos riscos ambientais advindos das desigualdades distributiva já mencionada na concepção das 'injustiças ambientais' abre caminhos para perceber e denunciar o ambiente de certos grupos sociais é privilegiado em detrimento de outros, emergindo, assim, o que se veio denominar "conflito ambiental" (ACSELRAD, 2010). Nesse sentido o processo das reivindicações, não ocorre de forma tranquila, indiferente e pacifica tanto em relação aos que pleiteia e os pleiteados.

Costa e Loureiro (2016 p.142) reportam sobre o movimento social e ecologia no Brasil no contexto dos conflitos, ilustra um grande precursor dessas lutas na figura de Chico Mendes, sindicalista, militante da esquerda do Partido dos Trabalhadores e lutador incansável dos povos da Floresta Amazônica. Sujeito lendário, um defensor do povo brasileiro, "mas o tratamento da mídia retorceu sua história ocultando a radicalidade social e política de sua luta" Não pode negar também a lutas dos movimentos dos Trabalhadores Sem Terra (MST) "chegando à conciliação histórica junto a grupos ambientalistas no processo de defesa de algumas áreas".

Para estes pensadores em 1997 foi assinado Pacto Chico Mendes, em que a direção do MST e grupos ambientalistas se comprometeu mutuamente a defender a justiça social e o acesso à terra sem reforçarem práticas destrutivas" não são simples os desafios encontrados de forma concreta em viabilizar "assentamentos nos moldes da produção coletivizada e por meio da agricultura ecológica, orgânica e variações outras, em um contexto de subordinação ao mercado. "Mas é exatamente aí que se explicitam os conflitos fundiários e de proteção natural, nos quais o MST cumpre função decisiva" (LOUREIRO, 2012, p. 52).

É valioso observar que o movimento ecológico possui em comum com os movimentos sociais, e o que os diferencia. Diversos são os movimentos sociais que se apresentam: os operários, os camponeses, os indígenas, as mulheres, os negros, os homossexuais, os jovens e tantos outros que se organizam e lutam. "Porém, há uma linha tênue entre todos estes movimentos os quais emergem partindo de determinadas condições de existência que Ihes dão organização" (LOUREIRO, 2012, p. 52).

Nessa perspectivadas sobre o movimento ecológico e social PortoGonçalves (2013, p.21) faz a seguinte indagação:

Existe uma condição ecológica? [...] Há um corpo operário, camponês, indígena, mulher, negro, homossexual e jovem [...] Não há, corpo ecológico enquanto condição social [...] Essa é uma diferença extremamente significativa: o movimento ecológico é mais difuso, não apreensível do mesmo modo que os demais corpos que se movimentam social e politicamente. Esse caráter difuso não desqualifica o movimento ecológico. Ao contrário, é a fonte da sua riqueza e dos seus problemas enquanto movimento político e cultural. Ao propugnar outra relação dos homens (sociedade) com a natureza, aqueles que constituem o movimento 
ecológico estão, na verdade, propondo outro modo de vida, outra cultura.

Nesse embate, o movimento ambientalista é um fenômeno materializado por concepções afinadas e antagônicas no que tange a compreensão da relação sociedade- natureza através do projeto societário que indique para a superação do atual padrão de sociabilidade. "De uma coisa não podemos duvidar: a atualidade do movimento ambientalista latino-americano parte de determinadas condições sociais de existência que Ihe conferem um caráter material e político!" perspectiva crítica da ecologia política existe variável que fomenta porque os movimentos sociais não podem ser vistos como secundários para este estudo, pois desqualificar as lutas dos movimentos sociais clássicos que reivindicaram as mazelas do capitalismo (COSTA; LOUREIRO 2016, p.145)

Os movimentos sociais na América Latina têm enfrentado e exposto desconexões do processo produtivo, como por exemplo: indústria de celulose agronegócio, a mineração, as reservas extrativistas e trouxeram para a arena política, tais questões! Finalmente, temos a segurança que o tema ecológico não é propriedade de nenhum agente social, nem mesmo dos que com eles buscam identificação, sendo uma dimensão da prática política e fator de identidade entre grupos e sujeitos (LOUREIRO; LAYRARGUES, 2013).

Os desafios pertinentes para a questão ambiental é promover espaços e estratégias capazes de enfrentar a hegemonia neodesenvolvimentista. Tendo como pressuposto que nenhuma luta ou mitigação de problemas socioambientais terá sucesso se não for capaz de articular as lutas locais e particulares. É nesta conjuntura surge o Desenvolvimento comunitário local como um dos modelos fundamentais na melhoria da qualidade de vida das comunidades e das gerações futuras (GÒMEZ; FREITAS; CALLEJAS, 2007; CARVALHO, 2002). Nessa perspectiva Andreoli e Campos (2017 p.137) colaboram que é local porque se desenvolve em comunidades com características específicas e problemas peculiares (território concreto e definido), "e comunitário porque se trata de um desenvolvimento no qual participam os sujeitos membros da comunidade de forma ativa, determinada e auto organizada. A condições para realização desse desenvolvimento e a participação".

Ao perceber que participar é a autopromoção dos sujeitos e o meio para a concretização da cidadania em suas várias dimensões, pode-se dizer que ela seria a negação direta das práticas pedagógicas assistencialistas e paternalistas, calçadas nas ideias neoliberais. Participar é, por conseguinte fortalecer os sujeitos para atuarem em favor de interesses ou necessidades comunitárias. É capaz transcender a oportunidade de decisões coletivas, como direito de usufruto dos bens materiais e culturais. Utilizando outro termo, significa "dar poder às pessoas e dotá-las dos meios materiais e intelectuais suficientes para exercer esse poder a favor do bem-estar geral" (GÓMEZ; FREITAS; CALLEJAS, 2007, p. 87).

A Educação Ambiental, nessa perspectiva, tem como possibilidades construir uma identidade que seja capaz de conduzir significado ao ser no mundo, tornando possível um pertencimento ao meio de vida e promovendo uma cultura do engajamento. Nesse sentido, o pertencimento ao lugar é condição necessária para a responsabilidade ambiental. 


\section{MOVIMENTO DOS ATINGIDOS PELA MINERAÇÃO-MAM}

A expansão da mineração no Brasil nos últimos 10 anos tem trazido impactos significativos para as comunidades e o meio ambiente, esse crescimento está relacionado com o Plano Nacional de Mineração 2030 (PNM - 2030) maior utilização dos bens naturais e flexibilizações das leis ambientais justificadas pelo capitalismo mineral. É notável que as atividades de extração potencializem inúmeras contradições, comuns segundo o Instituto de Estudos Socioeconômicos (INESC, 2016) muitas partes do território brasileiro ecoam denúncias de injustiças socioambientais provocados pela mineração e sua cadeia produtiva de escoamento, transformação e exportação. Concomitantemente, reforça o papel primário da economia exportadora tornando uma sangria rumo ao exterior, com o escoar desses bens nos nossos portos.

Segundo Instituto Brasileiro de Mineração (IBRAM, 2015) o território brasileiro se tornou uma detentor de produções significantes na balança comercial dos elementos de: nióbio, manganês, ferro, tântalo, bauxita, crisotila, magnesita, rochas ornamentais e grafita, em que premiou o setor com investimento de 53,6 bilhões de dólares no ano 2014. Como crescimento da atividade mineral, redução de custos e devastação socioeconômica substanciada pelo lucro e política perversa desigualdade distributiva provém um campo fértil para lutas sociais de resistência dos povos atingidos pela atividade de mineração.

Movimento pela Soberania Popular na Mineração (MAM) sua história se desenvolve entre os anos 80 e 90 um movimento social em que "emerge das lutas localizadas e de mobilização contra os projetos agropecuários e de mineração na Amazônia evidenciando as contradições do capital mineral dos territórios". Esse período pós-regime militar nasce vários movimentos sócias com bandeira de lutas os direitos trabalhistas, estrutura fundiária e impactos socioambiental de grandes empreendimentos. Nesse contexto o MST já havia consolidado no sul do país nos anos 80 e também já articulava ações na luta pela terra em Carajás no Pará. Estado que posterior viera a registrar grandes partes de conflitos no campo. No final desse período, as lutas nesse território se caracterizavam para além das questões iniciais adentrado nas contradições do modelo mineral e no poder das mineradoras (MAGNO, 2017 p.307).

Nesse contexto, conforme salienta Magno (2017), nos anos 2000, o discurso das contradições na atividade de mineração ganha ênfase nos movimentos sociais, O MST do Pará realizou ações como o plebiscito popular para a reestatização da empresa Vale. Em 2007 a segunda ação foi a ocupação dos trilhos de ferro Carajás-São Luís (45 dias de duração) com notória participação social, parando um dos complexos minerários do país, um ano após em Serra Pelada (Pará) o movimento agregou a participação dos trabalhadores das minas, Nesse lapso temporal surge o Movimento dos Trabalhadores das Minas(MTS) para debaterem a questão mineral e direito dos trabalhadores especialmente os garimpeiros. Tomava forma principalmente em Juriti (Pará) nas comunidades rurais, quilombolas mobilizações sociais na lutam contrapondo a exploração da bauxita nesses territórios. Dessa maneira, reconhecia os primeiros atingidos pelas minerações: trabalhadores das minas, camponeses, quilombolas etc.

Com crescimento das extrações de minérios advindos PNM20-30 tornouse necessária a formalização de um movimento com abrangências além do 
estado do Pará e grande demais para o MST manter essas demandas, Os atingidos especificamente pela atividade de mineração tinha necessidade de formalização do movimento. Assim sendo a primeira reunião para formação do MAM aconteceu em abril 2012 com políticas de fortalecimento, resistência os projetos Carajás e ainda um discurso sobre o modelo mineral brasileiro. $O$ segundo encontro conforme Oliveira (2013) foi realizado em maio de $2013 \mathrm{com}$ inclusão em pauta no só os atingidos, mas os ameaçados aqueles poderão sofrer danos com implantação de novos empreendimentos.

Assim o Movimento dos atingidos pela Mineração traça com objetivos defender os interesses e direitos dos povos que são atingidas por projetos de mineração de forma direta e indireta em todo território brasileiro. Conforme salienta Oliveira (2013, p.38):

Defender os interesses e direitos das populações que são atingidas por projetos de mineração em todo território brasileiro e mobilizar-se contra o atual modelo de exploração mineral em vigor que beneficia apenas o capital, através de grandes empresas brasileiras e transnacionais, com participação do Estado. O MAM se propõe a ser um movimento popular, de caráter anticapitalista e antiimperialista, que busca a realização de lutas de massa. É uma experiência que surge dentro do âmbito da Via Campesina Brasil, tendo o apoio dos demais movimentos que compõe a Via.

O MAM é representado em 10 estados são eles: Pará, Minas Gerais, Maranhão, Piauí, Ceará, Bahia, Goiás, São Paulo, Espírito Santo e Distrito Federal. A espacialidade do movimento não se restringe onde se tem empreendimento com participação de trabalhadores da mineração, garimpeiros, sindicatos, movimentos ambientalistas em geral e entidades e instituições de apoio e assessoria, tais como ONG's, universidades e institutos de pesquisa. Em suma pode se reafirmar as pautas desse movimento e ações propostas conforme quadro abaixo.

Quadro 1: Pautas e propostas

\begin{tabular}{|l|l|}
\hline \multicolumn{1}{|c|}{ PAUTAS } & \multicolumn{1}{|c|}{ PROPOSTA } \\
\hline Territórios livres de mineração & $\begin{array}{l}\text { Não se deve minerar próximo a barragens } \\
\text { que abastecem cidades, em balneários e } \\
\text { locais que possuam patrimônio histórico } \\
\text { cultural/arqueológico ou natural. }\end{array}$ \\
\hline Ritmos de mineração & $\begin{array}{l}\text { A exploração mineral não pode ser feita de } \\
\text { qualquer maneira e a qualquer custo, já que } \\
\text { as reservas minerais são finitas e o impacto } \\
\text { ambiental desta atividade é irreversível. }\end{array}$ \\
\hline $\begin{array}{l}\text { Assegurar os direitos } \\
\text { trabalhistas }\end{array}$ & $\begin{array}{l}\text { O histórico de violação de direitos } \\
\text { trabalhistas em áreas de mineração é muito } \\
\text { alto e, por este motivo, é preciso traçar }\end{array}$ \\
\hline
\end{tabular}




\begin{tabular}{|c|c|}
\hline & $\begin{array}{l}\text { estratégias que protejam a integridade física } \\
\text { e social dos trabalhadores do setor. }\end{array}$ \\
\hline Áreas indígenas & $\begin{array}{l}\text { Respeitar a convenção } 169 \text { da OIT sobre o } \\
\text { direito de consentimento e veto dos povos } \\
\text { indígenas sobre a expansão da mineração } \\
\text { em seus territórios. }\end{array}$ \\
\hline Democracia e transparência & $\begin{array}{l}\text { Os processos de licenciamento ambiental } \\
\text { não são transparentes. É preciso, então, } \\
\text { garantir a participação de agentes idôneos } \\
\text { durante nos mesmos, fiscalizando e } \\
\text { averiguando os impactos ambientais de } \\
\text { empreendimentos minerários. É necessário } \\
\text { também que laudos e pareceres contrários a } \\
\text { estes empreendimentos sejam respeitados } \\
\text { para que a sociedade civil tenho } \\
\text { conhecimento das condições de operação } \\
\text { dos mesmos, bem como de seus riscos. }\end{array}$ \\
\hline $\begin{array}{l}\text { Direito de consulta e veto de } \\
\text { comunidades }\end{array}$ & $\begin{array}{l}\text { Garantir que as comunidades atingidas por } \\
\text { mineração participem efetivamente do } \\
\text { processo de licenciamento ambiental destes } \\
\text { empreendimentos, através de consulta e de } \\
\text { poder de veto em audiências deliberativas. }\end{array}$ \\
\hline Plano de fechamento de Minas & $\begin{array}{l}\text { Após a finalização das atividades extrativas } \\
\text { é preciso que exista um plano que as } \\
\text { empresas cumpram para garantir a } \\
\text { recuperação ambiental da área degradada. }\end{array}$ \\
\hline
\end{tabular}

Fonte: Magno, 2017.

\section{CONCLUSÕES}

Diante da abordagem teórica advinda de uma revisão bibliografia é possível mencionar que os movimentos sociais são importantes porque representam alguma demanda social, política e econômica, muitas vezes as ações, demandas e princípios articulados pelos pleitos coletivos podem modificar e/ou interferir nas políticas públicas, realidades sociais entre outros.

Nessa conjuntura, os movimentos sociais que defendem o uso coletivo dos bens ambientais, conservação desses bens, faz uma análise critica da utilização desses recursos em larga escala pelo sistema capitalista de produção, enfim os que atuam com bandeira de luta a vertente socioambiental deixam o legado positivo de como as ações coletivas dos movimentos sociais pode contribuir para uma educação ambiental que pode modificar, transformar e ainda fornece instrumentos de demandas utilizadas para desenvolvimento local ou até nacional pode interferir positivamente, pois, acreditamos que tais discursões podem colaborar para a real contradição que envolve a sociedade capitalista. Ainda sim, é crucial discorre que existe literatura que difere movimentos sociais com viés ambiental classificando o como movimento ecológico, por não existir um corpo ecológico como acontece, por exemplo, nos movimentos mulheres, 
homossexuais. Mas isso não diminui o legado desses movimentos na educação ambiental.

É pertinente ressaltar ainda a função social que tem os movimentos, nesse estudo nota-se como o MAM atua na defesa dos direitos daqueles afetados pela modelo extração mineral do País e as articulações como movimento contribui para uma educação ambiental transformadora, assim conforme relata Magno ( 2017p.2-8) essas ações pode modificar a historia de uma região com aconteceu entre 2010-2016 a campanhas pelas aguas das quais decorreu no cancelamento do mineroduto na região de Minas Gerais em Viçosa da empresa transnacional Ferrous Resources do Brasil. Pretendia atravessar 22 municípios em três estados brasileiros (Minas Gerais, Rio de Janeiro e Espírito Santo) e afetaria as áreas de nascentes dos cursos d'água que abasteciam tanto os atingidos mais diretamente quanto as cidades ao longo do seu trajeto, onde a água é destinada para o consumo da população urbana".

O MAM não tem com pauta fechamentos de empreendimentos, $O$ movimento trabalha no sentindo que respeitem os direitos dos trabalhadores, dos camponeses e dos bens naturais que afetem um determinado território em detrimento de uma atividade mineral, para que os recursos minerários não sejam extraídos sobrepondo e esmagando o direito dos atingidos/ameaçados.

\section{REFERÊNCIAS}

ACSELRAD, H. Ambientalização das lutas sociais o caso do movimento de justiça ambiental. Estudos Avançados (USP. Impresso), v. 24, p. 103-120, 2010.

ANDRELOI; V. M. CAMPOS, T. Contribuições da Educação Ambiental para o desenvolvimento comunitário local na llha do Mel (Paraná). Rev. Eletrônica Mestr. Educ. Ambient. Rio Grande, Edição especial XVI Encontro Paranaense de Educação Ambiental, p. 132-149, set. 2017. E-ISSN 1517-1256 disponível em:

$<$ https://www.researchgate.net/publication/324021181_Contribuicoes_da_Educ acao_Ambiental_para_o_desenvolvimento_> Acesso em 4 jan 2019.

BRASIL. Constituição da República Federativa do Brasil. Brasília, DF: Senado Federal: Centro Gráfico, 1988. 292 p.

BRASIL. Lei 9795 de 27 de abril de 1999. Dispõe sobre a Educação Ambiental, institui a Política SENADO FEDERAL. Agenda 21. Brasília. 1997.

CARVALHO, I. C. M. A invenção ecológica: narrativas e trajetórias da educação ambiental no Brasil. Porto Alegre: Ed. Universidade /UFRGS, 2001.

CRESWELL, John W. Projeto de pesquisa: métodos qualitativo, quantitativo e misto. 3 ed. Porto Alegre: Artmed, 2010.

COSTA.A. C; LOUREIRO, C. F. B. Os movimentos sociais e a questão ambiental na perspectiva de Enrique Dussel. Argumentum, Vitória (ES), v. 8, n.1, p. 140157, jan./abr. 2016. 
FOLADORI, G. Limites do desenvolvimento sustentável. Campinas: Editora da Universidade Estadual de Campinas, 2001. $221 \mathrm{p}$

FREIRE, Paulo. Conscientização: Teoria e Prática da Libertação. Uma Introdução ao Pensamento de Paulo Freire. São Paulo: Cortez \& Moraes, 1979.

FREIRE Ação cultural para a liberdade. 5 ed., Rio de Janeiro, Paz e Terra. 1981.

GOHN, M. G. 500 anos de lutas dos sociais no Brasil: movimentos sociais, ONGs e o Terceiro setor. Mediações. Londrina, v.5,p.11-40.

GOHN, M. G. Teoria dos movimentos sociais: paradigmas clássicos e contemporâneos. São Paulo: Loyola: 2006. 363p.

GÓMEZ, J. A.; FREITAS, O. M; Pereira de; CALLEJAS, Germán Vargas. Educação e Desenvolvimento Comunitário Local: perspectivas pedagógicas e sociais da sustentabilidade. Porto: Profedições, 2007.

GROSSI, M. Questão ambiental e a construção do outro metabolismo social: contribuições e desafios aos movimentos indígenas e campesinos. Argumentum, Vitória (ES), n.1 p. 32-45, jan./jun. 2013.

HERCULANO, S. O clamor por justiça ambiental e contra o racismo ambiental. InterfacEHS (Ed. português), v. 3, p. 1-20, 2008.

Instituto de Estudos Socioeconômicos (INESC). Disponível em: $<$ http://www.inesc.org.br/search?Subject\%3Alist=minera\%C3\%A7\%C3 \%A3o>. Acesso em: 15. Abr. 2016.

INSTITUTO BRASILEIRO DE MINERAÇÃO. Informações sobre a economia mineral brasileira 2015. Brasília, 2015. Disponível em: <http://www.ibram.org.br/sites/1300/1382/00005836.pdf>. Acesso em: 23. Jan. 2017

LEFF, E. Epistemologia Ambiental. Tradução de Sandra Venezuela. Cortez, São Paulo, 2002.

LOUREIRO, C. F. B. Trajetória e fundamentos da educação ambiental. Cortez, São Paulo, 2012.

LAYRARGUES, P. P.; LIMA, G. F. C. As macrotendências político-pedagógicas da educação ambiental brasileira. In: Ambiente \& Sociedade, v. 17, p. 23-40, 2014.

LOUREIRO, C. F. B., LAYRARGUES, P. P. Ecologia política, justiça e educação ambiental crítica: perspectivas de Aliança contra-hegemônica. Trab. Educ. Saúde, Rio de Janeiro, v. 11, p. 53 - 71, 2013.

MAGACHO, L. N. Pesquisa em educação ambiental e movimentos sociais: um estudo sobre teses e dissertações brasileiras. 2017.145 f. Mestrado em 
EDUCAÇÃO. Universidade Estadual Paulista Júlio de Mesquita Filho de Rio Claro, São Paulo.

MAGNO, L. Espacialidade e identidade política dos atingidos por mineração no Brasil: teorias, escalas e estratégias. Tese (doutorado) Programa de Pósgraduação em Geografia da Universidade Federal de Santa Catarina-UFSC, Florianópolis, 2017, p.382.

MARX, K. O capital. Crítica da economia política. São Paulo: Abril Cultural, 1983(os economistas).

PAZ, M. D. S. D. S. Educação Ambiental em escolas do campo: Possibilidades e Desafios. 2017. 105f. Texto para Defesa (Mestrado) - Programa de PósGraduação em Educação e Contemporaneidade - Departamento de Educação, Universidade do Estado da Bahia, Salvador, 2017.

MINAYO, M. C. D. S. (org.); GOMES, S. F. DESLANDES, R.G. Pesquisa Social: teoria, método e criatividade. 34. ed. Petrópolis: Vozes, 2014. (Coleção Temas Sociais).

PORTO-GONÇALVES, C. W. Lutas sociais, Lutas ecológicas. In: C.W. PORTOGONÇALVES. Os (Des) caminhos do meio ambiente. São Paulo: Contexto, 2013. p. $18-40$.

FONSECA, J. J. S. Metodologia da pesquisa científica. Fortaleza: UEC, 2002. 